\title{
Environmental influences on attraction: Effects of heat, attitude similarity, and personal evaluations*
}

\author{
PAUL A. BELL and ROBERT A. BARON \\ Purdue University, West Lafayette, Indiana 47907
}

\begin{abstract}
Eighty undergraduate males received either a positive or a negative personal evaluation from an attitudinally similar or dissimilar confederate. Experimental sessions were conducted under either comfortably cool $\left(73^{\circ} \mathrm{F}\right)$ or uncomfortably hot $\left(92^{\circ} \mathrm{F}\right)$ environmental conditions. Attraction toward the confederate was primarily influenced by the personal evaluation and attitude similarity variables. Although high ambient temperatures markedly decreased Ss' affective state, exposure to heat did not consistently lower their attraction toward the confederate. Several procedural differences are proposed to account for the inconsistent influence of heat on attraction reported in the present and previous research.
\end{abstract}

The influence of the physical environment on human social behavior has become the focus of considerable research in recent years. One of the environmental variables most frequently studied in this regard has been that of heat (i.e., high ambient temperatures). Intuitively, the discomfort caused by exposure to stifling hot environmental conditions would seem to facilitate a variety of responses or emotional reactions such as irritation, short tempers, and flight. Empirically, high ambient temperatures have indeed been shown to decrease interpersonal attraction (Griffitt, 1970; Griffitt \& Veitch, 1971) and either to inhibit or to facilitate human aggression, depending on other factors in the physical and social environment (Baron, 1972; Baron \& Bell, in press; Baron \& Lawton, 1972).

From a theoretical perspective, much of the environmental resarch on interpersonal attraction has been interpreted within the context of Byrne's (1971) reinforcement-affect model of attraction. According to this model, reinforcing stimuli, such as attitude statements and personal evaluations, evoke implicit positive and negative affective responses from observers (Byrne \& Rhamey, 1965). Any previously neutral stimulus, such as the stimulus person to whom the attitudes or personal evaluations are attributed, can also become capable of eliciting the implicit affective responses through association with the positively or negatively reinforcing stimuli. Since this implicit affect theoretically mediates attraction toward the stimulus person, it follows that lowering the overall affective state of the observer through exposure to uncomfortably high ambient temperatures or other unpleasant environmental stimuli, will consequently decrease attraction toward the

\footnotetext{
*The authors would like to express their appreciation to Frank Dougherty and Stan Lelak for their assistance in the collection of the data.

This research was supported by a grant (GS-35176) from the National Science Foundation to Robert A. Baron. Requests for reprints should be sent to Paul A. Bell, Department of Psychological Sciences, Purdue University, West Lafayette, Indiana 47907.
}

stimulus person (see, e.g., Griffitt, 1970).

The reinforcing stimuli employed by Griffitt (1970) and by Griffitt and Veitch (1971) consisted of attitude statements attributed to a bogus stranger which were similar or dissimilar to the attitudes held by Ss. As would be predicted by the reinforcement-affect model, exposure to high ambient temperatures decreased attraction toward both similar and dissimilar strangers. Additional research on this at traction model has shown that stimuli embodying larger magnitudes of reinforcement than attitude statements, such as positive and negative personal evaluations, evoke stronger affective responses and thus have a more pronounced effect on attraction (Byrne \& Rhamey, 1965). It follows from the reinforcement-affect model, moreover, that exposure to heat will have a negative effect on the overall affective state of Ss, and consequently on their attraction responses, even when stimuli with very large magnitudes of reinforcement are employed as the primary determinant of attraction.

The purpose of the present experiment, then, is that of extending Griffitt's research by examining the effects on attraction of exposure to high ambient temperatures when stimuli having relatively large magnitudes of reinforcement are also used to manipulate attraction. Specifically, it is predicted that exposure to high ambient temperatures will decrease feelings of comfort, and consequently decrease attraction toward a stimulus person. It is further hypothesized that this influence of heat will be independent of the effects on attraction of similar or dissimilar attitudes and positive or negative personal evaluations associated with the stimulus person.

\section{METHOD}

\footnotetext{
Subjects

Forty male students enrolled in sections of elementary psychology served as Ss. Participation in the experiment satisfied part of a course requirement.
} 
Design

A 2 by 2 by 2 factorial design was employed, based on two levels of ambient temperature (cool, hot), two levels of personal evaluation (positive, negative), and two levels of attitude similarity (similar, dissimilar). Five Ss were randomly assigned to each cell of the design.

\section{Procedure}

When Ss arrived for their experimental appointments, a male E explained they would be participating, along with another individual (actually a male confederate), in an experiment designed to examine the influence of temperature and humidity upon physiological reactions and performance. The $\mathrm{E}$ then conducted the $\mathrm{S}$ and confederate into the laboratory and, as part of the cover story, took a measure of their blood pressure. He also asked both participants at this time to complete a personal feelings scale (PFS), ostensibly for the purpose of comparing subjective and physiological reactions. The PFS (see Griffitt, 1970) contained six seven-point scales along which Ss rated their current feelings (comfortable-uncomfortable, bad-good, high-low, sad-happy, plesant-unpleasant, negative-positive).

Following these procedures, the $\mathrm{S}$ and confederate participated in a "complex social perception and interpersonal judgment task." In this task they each completed a 10-item attitude survey and used the information contained in each other's attitudes to rate one another on a number of personal traits, using Byrne's (1971) interpersonal judgment scale (IJS). The E arranged for the confederate to perform the task first, so that this person had an opportunity to complete his own attitude survey after examing the S's survey. More specifically, he completed his survey so as to agree with nine (similar condition) or only one (dissimilar condition) of the Ss attitudes. In addition, the confederate completed his IJS to reflect a very positive (e.g., intelligent, knowledgeable, well adjusted ) or very negative (i.e., unintelligent, unknowledgeable, maladjusted) evaluation of the S (see Byrne \& Rhamey, 1965, for exact ratings). The $S$ then performed the "social perception" task after examing both the bogus attitudes and bogus personal evluation of the confederate.

After the S had completed his judgments of the confederate, the E collected his IJS, administered a second PFS, and took another blood pressure reading from both the $S$ and confederate. $\mathrm{He}$ then asked both participants to complete a postexperimental questionnaire which required that they rate (on seven-point scales) the perceived temperature in the experimental rooms (very cool-very warm), the perceived favorableness of the evaluation from their partner (very unfavorable-very favorable), and the number of attitudes on the survey on which both participants generally agreed.

Manipulation of ambient temperature. Ambient temperature was varied by means of air conditioners and electric heaters. In the cool condition, average before and after temperatures in the S's room were both $73.3^{\circ} \mathrm{F}$, and in the hot condition these average temperatures were $92.3^{\circ} \mathrm{F}$ and $92.5^{\circ} \mathrm{F}$, respectively. Humidity was held relatively constant by means of cool-mist humidifiers, with readings averaging between $42.5 \%$ and $45.6 \%$.

\section{RESULTS}

\section{Affect}

The main dependent measure of affective state was the sum of the six subscales of the PFS, scored individually from 1 (most negative) to 7 (most positive) for a total possible range of 6 to 42 . An analysis of variance based on these scores indicated a significant main effect for temperature $(F=9.27, \mathrm{df}=1 / 32$, $\mathrm{p}<.005$ ), as well as marginally significant main effects
Table 1

Mean Ratings of Attraction as a Function of Ambient Temperature, Personal Evaluations, and Attitude Similarity

\begin{tabular}{lccccc}
\hline & \multicolumn{2}{c}{$\begin{array}{c}\text { Cool Temperature } \\
\text { Evaluation }\end{array}$} & & \multicolumn{2}{c}{$\begin{array}{c}\text { Hot Temperature } \\
\text { Evaluation }\end{array}$} \\
\cline { 2 - 3 } \cline { 5 - 6 } \cline { 5 - 6 } & Positive & Negative & & Positive & Negative \\
\hline $\begin{array}{l}\text { Similar } \\
\text { Attitudes } \\
\begin{array}{l}\text { Dissimilar } \\
\text { Attitudes }\end{array}\end{array}$ & 12.0 & 8.6 & & 11.8 & 6.8 \\
\hline
\end{tabular}

for personal evaluations $(F=2.92, \mathrm{df}=1 / 32, \mathrm{p}<.10)$ and attitude similarity $(\mathrm{F}=2.59$, $\mathrm{df}=1 / 32, \mathrm{p}<.12)$. Thus, as anticipated, high ambient temperatures, and to some extent negative personal evaluations and dissimilar attitudes, decreased Ss' personal feelings.

\section{Attraction}

The principal dependent measure of attraction was the sum of the likability and desirability as a work partner subscales of the IJS (see Byrne, 1971). Examination of the mean attraction scores from this index, as presented in Table 1, suggests that in accordance with the affect measure, heat, negative personal evluations, and dissimilar attitudes decreased attraction toward the confederate. An analysis of variance performed on these data, however, yielded only a main effect for the personal evaluation variable $(F=$ 43.60, $\mathrm{df}=1 / 32, \mathrm{p}<.0001)$. Separate analyses performed on the two attraction subscales, however, revealed main effects for similarity $(\mathrm{F}=4.26, \mathrm{df}=1 / 32$, $\mathrm{p}<.05)$ and evaluations $(\mathrm{F}=34.78, \mathrm{df}=1 / 32$, $\mathrm{p}<.0001)$ on the likability subscale, and a strong main effect for evaluations $(F=38.72, d f=1 / 32, p<.0001)$, as well as a marginally significant main effect for temperature $(F=2.88, \mathrm{df}=1 / 32, \mathrm{p}<.10)$ on the subscale measuring desirability as a work partner in an experiment. Thus, there was some indication that attraction toward the confederate was influenced by all three factors, but ambient temperature exerted somewhat weaker effects on such reactions than was the case in previous research (e.g., Griffitt, 1970).

\section{Postexperimental Questionnaire}

The items on the questionnaire were designed as manipulation checks. Analyses of these data revealed, not surprisingly, that Ss percevied the temperature in the laboratory to be warmer in the hot than cool condition $(F=112.04, \mathrm{df}=1 / 32, \mathrm{p}<.0001)$, that Ss perceived the evaluation they received to be more favorable in the positive than in the negative condition $(\mathrm{F}=49.13 \mathrm{df}=$ $1 / 32, p<.0001)$, and that Ss perceived more attitude agreement in the similar than dissimilar condition $(\mathrm{F}=$ 115.96, $\mathrm{df}=1 / 32, \mathrm{p}<.0001)$ and in the positive than negative evaluation condition $(F=24.16, d f=1 / 32$, $\mathrm{p}<.0001)$. 


\section{DISCUSSION}

The results offer clear support for the hypothesis that exposure to high ambient temperatures markedly reduces Ss' overall affective state. However, contrary to original predictions, the subsequent effects of heat on interpersonal attraction were less clear-cut than those observed in previous research (e.g., Griffitt, 1970; Griffitt \& Veitch, 1971). One possible explanation for this discrepancy involves procedural differences between the present and earlier studies. In the Griffitt experiments, the stimulus person was not present in the experimental rooms, and the only exposure of Ss to this person was through the bogus attitude survey. In the present experiemnt, however, Ss actually shared the laboratory experience with the stimulus person. In the hot condition, this situation may have served as an instance of "shared suffering," a type of experience which has been found to increase interpersonal attraction (e.g., Latané, Eckman, \& Joy, 1966). The finding that exposure to heat did not decrease the likability of the stimulus person but did tend to decrease desire to work in an experiment with this person lends further support to this "shared suffering" explanation. Additional research in which degree of direct interaction between the $S$ and confederate is systematically varied would be helpful in further testing this explanation.

Other procedural differences between the present study and those conducted by Griffitt may also account for the discrepancy in the influence of heat on attraction. For example, the Griffitt studies employed high ambient temperatures approximately $10^{\circ} \mathrm{F}$ higher than those used in the current experiment. Although the experimental rooms in the present study were judged by $S$ s to be quite uncomfortable and unpleasant in the hot condition, even higher temperatures may be necessary to demonstrate any consistent effects on attraction.
Still another explanation for the failure of the present experiment to demonstrate a clear relationship between ambeint temperature and attraction is that the personal evaluation manipulation may have been so strong (accounting for $53 \%$ of the variance) as to render any effect of temperature on attraction relatively undetectable. Additional research employing a wider range of temperatures and a larger number of levels of personal evaluations and attitude similarity may provide additional evidence concerning the validity of these explanations.

\section{REFERENCES}

Baron, R. A. Aggression as a function of ambient temperature and prior anger arousal. Journal of Personality \& Social Psychology, 1972, 21, 183-189.

Baron, R. A., \& Bell, P. A. Aggression and heat: Mediating effects of prior provocation and exposure to an aggressive model. Journal of Personality \& Social psychology, in press. Baron, R. A., \& Lawton, S. F. Environmental influences on aggression: The facilitation of modeling effects by high ambient temperatures. Psychonomic Science, 1972, 26, 80-83.

Byrne, D. The attraction paradigm. New York: Academic Press, 1971.

Byrne, D., \& Rhamey, R. Magnitude of positive and negative reinforcements as a determinant of attraction. Journal of Personality \& Social Psychology, 1965, 2, 884-889.

Griffitt, W. Environmental effects on interpersonal affective behavior: Ambient effective temperature and attraction. Journal of Personality \& Social Psychology, 1970, 15, 240-244.

Griffitt, W., \& Veitch, R. Hot and crowded: Influence of population density and temperature on interpersonal affective behavior. Journal of Personality \& Social Psychology, 1971, $17,92-98$.

Latané B., Eckman, J., \& Joy, V. Shared stress and interpersonal attraction. Journal of Experimental Social Psychology Supplement, 1966, 1, 80-94.

(Received for publication August 2, 1974.)

\title{
Relative weighting of positive and negative information and confidence in reports of behavioral intentions*
}

\author{
EMIL J. POSAVAC* \\ Loyola University of Chicago, Chicago, Illinois 60626
}

\begin{abstract}
Trait descriptions that varied in polarity from a neutral description were formed in order to compare the relative weights of positive and negative traits on reports of behavioral intentions (BIs). Forty-four Ss made marital BI judgments, and 82 Ss reported employ BIs. Negative traits were weighted more heavily than positive traits. Confidence in BI reports increased as the descriptions increased in polarity; but negative information did not consistently evoke more confidence than positive information. Hypotheses suggesting different patterns of responses to marital and employ BIs were not supported.
\end{abstract}

Hamilton and Huffman (1971) showed that negative information is weighted more heavily than positive

*Sponsored by E. B. Zechmeister, who takes full editorial responsibility for it.

Jack McKillip, Paul Lavrakas, and Susan Green are thanked for help at various stages of this experiment. Reprints may be obtained from the author at the Department of Psychology, 6525 North Sheridan R oad, Chicago, Illinois 6026. information in a person perception task using trait descriptions as stimuli. They also showed that the information integration principles (e.g., Anderson, 1967) developed using evaluative judgments can be applied to judgments of activity and potency. Posavac and McKillip (1972) extended this line of inquiry to reports of behavioral intentions (Triandis, 1965) and to confidence 